\title{
安徽宿县夹沟寒武系-奥陶系界线 地层的碳氧同位素研究
}

\author{
方一亭 沈渭洲 刘 燕 黄燿生
}

(南京大学地球科学系, 南京 210008)

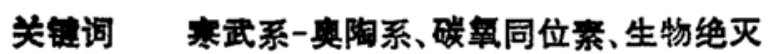

国际上对寒武系-奥陶系界线的研究近年来已取得很大进展,很可能划定在 Tremadocian 的底界,这与我国习惯采用的界线是一致的. 这一界线上、 下的生物群面貌发生了全球规模的变化, 繁荣于寒武纪的 三叶虫等生物, 到了寒武纪末期遭到了大规模的绝灭. 在 我国,已经在前寒武系-寒武系 ${ }^{[1]}$ 、泥盆系-石炭系 ${ }^{[2]}$ 、二叠 系一三叠系 ${ }^{[3]}$ 界线地层上发现了碳氧同位素组成 的 突然变 化, 指示了生物绝灭事件的存在. 同样, 寒武系一系陶系界 线地层的碳、氧同位素组成也应对寒武纪末期的生物绝灭 事件有所反映. 为此, 笔者选择安徽省的标准地层剖面之 - 一一宿县夹沟镇赵集 (图 1) 三山子组进行系统的碳、氧 同位素研究。

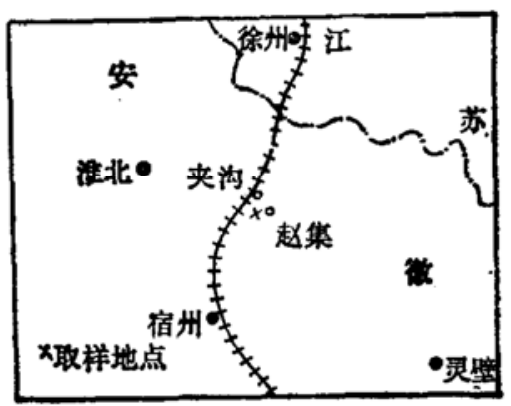

图 1 安徽宿县赵集剖面交通 位置示意图

\section{1 地 质 背 景}

三山子组分布于淮北、徐州一带,是一个寒武系-奥陶系的跨时岩石地层单位 ${ }^{[4,5]}$. 它主要 由微晶和细晶白云岩组成, 上部夹有遂石条带. 三山子组之下为上寒武统凤山组, 主要为豹皮 状微晶灰岩; 之上为下奥陶统贾汪组, 由薄层微晶白云岩和杂色页岩组成. 赵集剖面中三山子 组露头良好,地层连续,交通方便. 依据化石,三山子组可分为两部分: 下部(1层)产有寒武纪 标准化石 Coreanocephalus anhuiensis, Mictosaukia 等; 上部(2 和 3 层)未见寒武纪常见的 索克虫类等三叶虫,出现的是奥陶纪的牙形刺 Oneotodus nakamurai、头足类及无铰腕足类动 物 Lingulella 等化石 ${ }^{[6,7]}$. 三山子组下部(1 层)和上部(2 和 3 层)也正好是寒武系和奥陶系的 界线. 三山子组在岩性上均以白云岩为主, 属同一个岩性组合, 但其生物群面貌却存在着两个 明显不同的组合,显示在研究区内存在有生物绝灭事件.

\section{2 分析结果和讨论}

样品的碳、氧同位素分析采用磷酸法 ${ }^{[8]}$. 样品制备由南京大学地球科学系中心实验室完 成, 质谱测定由地质矿产部无锡石油中心实验室用 MAT-250 质谱仪完成. 对同位素标准:“北 
大 $7901^{n}$ 测定的 $\delta^{13} \mathrm{C}(\mathrm{PDB})$ 为 $2.62 \%$, $\delta^{18} \mathrm{O}(\mathrm{PDB})$ 为 $-5.47 \%$ 。样品分析精度优于 $0.1 \%$ 。

对赵集剖面三山子组跨时地层单位共系统采集 16 个样品. 样品新鲜,无蚀变. 碳、氧同

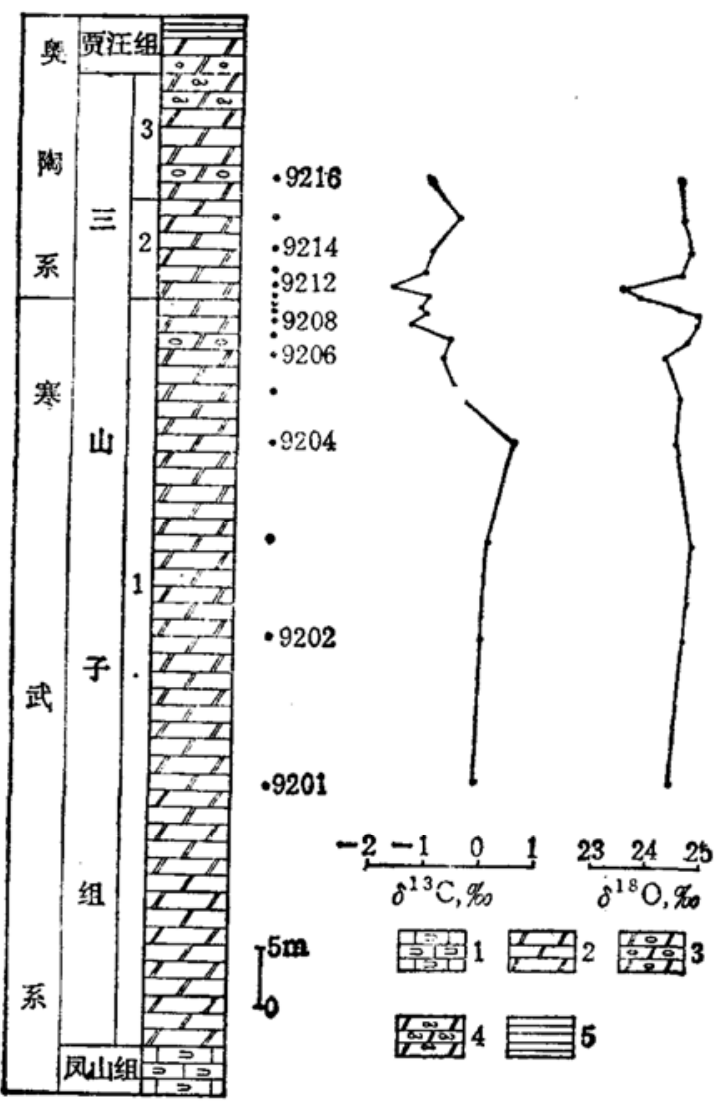

图 2 安徽宿县夹沟赵集剖面寒武系-奥陶系三 山子组白云岩的碳、氧同位䋈组成

1.妁皮状微晶灰岩, 2 .白云岩, 3.竹叶状白云岩, 4.含星石条带状白云岩, 5.页岩

位素分析结果列于图 2. 这些数据的对比研 究表明, 寒武系-奥陶系三山子组白云岩的 碳、氧同位素组成具有如下特点:

(1) 晚寒武世三山子组 1 层白云岩的碳 同位素组成变化小, $\delta^{13} \mathrm{C}$ 值为 $-0.58-0.51 \%$, 十分接近于正常海相碳酸盐岩石的平均 $\delta^{13} \mathrm{C}$ 值 ${ }^{[9]}$, 显示以 ${ }^{13} \mathrm{C}$ 相对富集为特征.

（2）早奥陶世三山子组 2 和 3 层白云岩 的碳同位素组成变化大, $\delta^{13} \mathrm{C}$ 值为 $-0.54-$ $-2.12 \%$, 明显地显示出 $\delta^{13} \mathrm{C}$ 值下降的特征.

（3）在寒武系-奥陶系界线附近,即三山 子组 1 层和 2 层分界处, 白云岩的碳同位素 组成发生明显的变化: 从下部层位（样号 $9205, \delta^{13} \mathrm{C}=-0.58 \%$ ）向上部层位（样号 $9212, \delta^{13} \mathrm{C}=-1.62 \%$ ), $\delta^{13} \mathrm{C}$ 值发生陡降, 在约 $3 \mathrm{~m}$ 范围内, $\delta^{13} \mathrm{C}$ 变化幅度大于 $1 \%$ 。

(4) 三山子组白云岩的氧同位素组成变 化不大, 除个别样品外, 其平均 $\delta^{18} \mathrm{O}$ 值 (24.62\%0) 接近于寒武-奥陶纪时期正常海相 碳酸盐岩石值 ${ }^{[103}$, 反映自成岩以来并未明显 受到雨水同位素交换作用的影响. 但在界线 附近, 白云岩的 $\delta^{18} \mathrm{O}$ 值同样显示出明显的变 化,即从下部(样号 $9209, \delta^{18} \mathrm{O}=24.77 \%$ ) 向 上部（样号 $9212, \delta^{18} \mathrm{O}=23.42 \%$ ）陡降,变化幅度大于 $1 \%$, 并显示出与碳同位素组成变化 相协调的特点 (图 2).

夹沟赵集剖面寒武系-奥陶系三山子组白云岩碳同位紊组成的变化特征与美国俄克拉何 马州寒武系-契陶系 Arbuckle 群界线地层碳同位素组成的变化特征非常相似,后者在界线地 层处 $\delta^{13} \mathrm{C}$ 值从 $0 \% 0$ 降至 $-2 \% 0^{[1]}$. 这表明由 $\delta^{13} \mathrm{C}$ 值突然下降所暗示的寒武纪-奥陶纪交界 时期的生物绝灭事件有可能是全球性的.

对于界线地层碳（氧）同位素组成的明显变化已提出多种假设, 其中最流行的是地外事 件 ${ }^{[12]}$ 和海平面变化 ${ }^{[13]}$ 两种假设. 地外事件说认为, 由于地外星体撞击地球产生的炽热冲击波 和大量尘埃使地球表面的气候条件发生急剧变化, 导致生物突然绝灭. 这些大规模死亡的生 物不可能及时被埋藏,它们在篻化、分解过程中释放出富 ${ }^{12} \mathrm{C}$ 和 ${ }^{16} \mathrm{O}$ 的 $\mathrm{CO}_{2}$ 气体. 后者与海水 中溶解碳产生同位素交换, 从而使沉积碳酸盐岩石的 $\delta^{13} \mathrm{C}$ (或 $\delta^{18} \mathrm{O}$ )值明显下降. 海平面变化 说认为, 在海平面下降(海退)时期, 由于大法架出露或浅海发育, 有祅质氧化速度增加, 使海水 中 ${ }^{12} \mathrm{C}\left({ }^{16} \mathrm{O}\right)$ 含量升高, 从而导致沉积碳酸盐岩石的 $\delta^{13} \mathrm{C}\left(\delta^{18} \mathrm{O}\right)$ 隆低. 本文所研究的夹沟赵集 剖面 寒武系-奥陶系三山子组白云岩的碳、氧同位素组成在界线处突然降低的原因还有待于 
进一步研究。

\section{3 结 论}

(1) 安徽宿县夹沟赵集剖面寒武系-奥陶系三山子组白云岩的碳、氧同位索组成在界线处 发生突然变化, $\delta^{13} \mathrm{C}$ 与 $\delta^{10} \mathrm{O}$ 值的变化幅度大于 $1 \%$.

(2) 碳、氧同位素组成的突变部位恰与寒武系-奥陶系界线相吻合, 也与化石研究显示的 生物绝灭事件相一致. 这表明, 界线地层的碳、氧同位素研究对于确定寒武系一䒩陶系界线、揭 示生物绝灭事件的存在和探索生物绝灭的原因具有重要的意义。

\section{䒧孝 文 献}

[1] 陈锦石等,科学通报, 1992,37(6): 540-542.

[2] 白顺良等, 北京大学学报(自终科学版), 1990, (4): 497-505.

[3] 陈镍石等,地质科学, $1984,(1): 88-93$.

[4] 安徽325地质队, 地质科技, 1974, (6): 21-28.

[5] 姚伦淇、王新平,北京大学学报(自然科学版), 1978,(4): 111-132.

[6] 安徽省区域地质调査队, 安地层志寒武系分册, 安徽科学技术出版社, 1988.

[7] 安徽省区域地质调查队,安微地层志奥陶系分侜, 安徽科学技术出版社, 1989 .

[8] 黄㸌生等,南京大学学报(自然科学肘), $1985,21(2): 361-370$.

[9] Keith, M. L, Weber, J. N., Geochim. Cosmochim. Acta, 1964, 28: 1787-1816.

[10] Lohmann, X. C., Walker, J. C. G., Geophys. Res. Lett., 1989, 16: 319-322.

[11] Gao, Guo-qiu, Land, L. S., Geochim. Cosmochim. Acta, 1991, 55: 2911-2920.

[12] Alvarez, L. et al, Science, 1980, 208: 1095-1108.

[13] Magaritz, M, Stemmerik, L, Earth Planet. Sci. Lett, 1989, 93: 233-240. 